nineteenth century by offering cover to manual workers in certain occupations. They were progressively extended to family members and other groups of workers, eventually including pensioners and the unemployed.

In many countries social insurance is now compulsory for most citizens, with payments usually taking the form of payroll taxes levied on employees and employers. Social solidarity is an important principle in these systems, with those who are better off subsidising the costs of health care for those who are less well off. Despite this, problems of equity arise, as in Germany, where tax rates are set by individual sickness funds and vary according to the membership of funds and their risk structure.

The study shows that social insurance funding does not of itself tackle inefficiencies in the delivery of services, which is why those who are responsible for health care funding have turned their attention towards reforming the arrangement for reimbursement. ${ }^{4}$ For hospitals this has meant greater interest in the use of global budgets; for doctors it has meant attempts to cap fees and closer scrutiny of clinical decision making.

As experience in different countries shows, widely varying admission rates, lengths of stay, costs per case, and other variables, almost regardless of how funding is provided, indicate that reforms that address weaknesses in delivery are at least as important as those that seek to introduce alternative systems of funding. This lesson has clearly not been lost on British governments. Twice in the past decade governments have examined and rejected the arguments for moving away from tax funding and instead focused on changing management and increasing competition.

While Glaser has performed an invaluable service in bringing together a large volume of data from different sources, he would be the first to acknowledge that information and ideas in themselves are insufficient to produce a change in policy. The United States, forever the land of paradox, "sponsors more research on health care financing than the rest of the world combined, but it has no health care financing system." The real obstacle to reform is the absence of political will. Without this will there is no way forward, and the United States may therefore resort to further research as a substitute for action.

The beneficiaries of this study may therefore be policy makers in other countries where the capacity to promote changes is much greater. Yet even outside the United States health care reform tends to be incremental rather than radical, as the fate of the Dekker reforms in the Netherlands shows. ${ }^{5}$ Given our limited understanding of what works and the inherent difficulties of translating ideas from one political system to another, this may be no bad thing. After an era of activism in health policy a period of caution may well be in order. As Glaser's work shows, there are no quick fix solutions to the problems of paying for health services, and a degree of humility on the part of those charged with running health services would be a welcome antidote to the rush to reform of recent years.

CHRIS HAM

Fellow in Health Policy and Management,

King's Fund College,

London W2 4HS

1 Ham C, Robinson R, Benzeval M. Health check. London: King's Fund Institute, 1990.

2 Klein R. On the Oregon trail: rationing health care. $B M \mathcal{F} 1991 ; 302: 1-2$.

3 Glaser WA. Health insurance in practice. San Francisco: Jossey-Bass, 1991

4 Glaser WA. Paying the hospital. San Francisco: Jossey-Bass, 1987.

5 Committee on the Structure and Financing of the Health Care System. Willingness to change. The Hague: Dutch Ministry of Health and Culture, 1987.

\title{
The management of "psychogenic" orofacial pain
}

\section{A collaborative attitude and antidepressants may help}

Chronic facial pain is an important health problem. It is impossible to measure the extent of distress that it causes patients and those who care for them, but society suffers as a consequence of the disability, loss of employment, litigation, compensation, and costs of treatment. Bonica estimated that five to seven million Americans suffered chronic pain in the face and mouth at a cost to society of over $\$ 4$ billion a year. ${ }^{1}$

Even when recognised syndromes with well defined causes and treatments, such as trigeminal neuralgia, are excluded there remains a large group of patients who pose major management problems for doctors and dentists. Lack of dialogue between doctors and dentists, and the gaps in dental knowledge among doctors and medical knowledge among dentists contribute to the problem. ${ }^{2}$

Various poorly categorised descriptions have been used, such as atypical face pain, atypical odontalgia, psychogenic pain, and, more recently, somatoform pain. ${ }^{3}$ Cohen has repeated the common observation that diagnoses that say what the disorder is not, rather than what it is, are unhelpful and again advocated a problem oriented view that could allow a positive intervention. ${ }^{4}$

Pain is subjective and a complex phenomenon with sensory, emotional, behavioural, and cognitive components. The International Association for the Study of Pain defines pain as "an unpleasant sensory and emotional experience associated with actual or potential tissue damage, or described in terms of such damage."' The understanding of a definition such as this, which emphasises the subjective and avoids any need to show tissue damage, offers an opportunity to offer a problem oriented approach in treatment. Such an approach may well include suggesting that pain relief is not the only goal.

Patients with facial pain have almost universally had negative experiences of treatment. Surgery has often failed, drugs have not worked, and numerous investigations have given normal results. In one study pain had been present for an average of four years before the patient attended a pain clinic. ${ }^{6}$ It does not help patients to be told there is nothing wrong, because in their experience there patently is.

No management can help unless the patient complies with it. In these patients that involves a synthesis between their own experience of, and beliefs about, pain, and those of their doctor, who has an altogether different appreciation of the situation from them. In an elegant view of this necessary synthesis Turk and Rudy advocate an explanatory and exploratory approach. They emphasise the need for information and for attempting to increase the concordance between the beliefs of the patient and the treatment offered. ${ }^{7}$ They also suggest emphasising adherence to treatment, rather than compliance. Adherence implies choice and mutuality in planning treatment with the active voluntary collaboration of the patient. Compliance implies that the patient simply follows the doctor's instructions. ${ }^{8}$ 
An admirable example of enhancing adherence by offering a synthesis that allows for the patients' pain beliefs is offered by Feinmann et al. ${ }^{9}$ They sidestep the psychological-physical divide neatly by offering an explanation of pain that emphasises the role of muscular tension in its genesis, then prescribe the antidepressant dothiepin hydrochloride, emphasising its muscle relaxing properties.

Antidepressants are the most successful and widely evaluated drugs used to treat these types of "psychogenic" facial pain, and their benefits seem to be independent of any antidepressant action. There is no good evidence to support the use of one drug over another, or of particular dosage regimens, although most trials have used doses over the equivalent of $100 \mathrm{mg}$ of amitriptyline a day. Treatment needs to be persisted with for several months. ${ }^{21011}$

When there is burning pain in the oral mucosae, treatment with vitamin B-1 may be useful, even in the absence of measurable deficiency. ${ }^{12}$ Benzodiazepines may be helpful, but their use should be avoided as dependence soon develops. Enhancement of the analgesic effects of antidepressants with low dose neuroleptics has been advocated, but recent evidence suggests that there is no benefit. ${ }^{13}$ Almost every author who writes on the subject says that surgery should be avoided and may make things worse.

Psychological treatments can be helpful, and their use has been well reviewed by Bond and Hughes. ${ }^{14}$ Such treatments include behaviour therapy, relaxation, biofeedback and hypnosis, and cognitive psychotherapies. Unfortunately, generally only psychiatric services have access to these. In spite of the calls of Bond and Hughes and many others for the establishment of regional multidisciplinary pain management units there are very few in the United Kingdom.

Chronic orofacial pain can be a disturbing problem for patient and doctor. If attention is paid to reconciling the patient's experiences and expectations of treatment with a proposed course of treatment the outcome can be successful and the prognosis good. These difficult patients can then become a rewarding group to treat.

Consultant in Psychological Medicine,

STEPHEN HUNTER

St Cadoc's Hospital, Caerleon,

Gwent NP6 IXQ

1 Bonica JJ. Pain research therapy. Past and current status and future needs. In: $\mathrm{Ng} \mathrm{LKY,} \mathrm{Bonica} \mathrm{JJ,}$ eds. Pain, discomfort and humanitarian care. Amsterdam: Elsevier, 1980:1-46.

2 Feinmann C, Harris M. Psychogenic facial pain. 2. Management and prognosis. Br Dent $\mathfrak{J}$ 1984;156:205-8.

3 American Psychiatric Association. Diagnostic and statistical manual of mental disorders. 3rd ed (revised). Washington, DC: American Psychiatric Association, 1987.

4 Cohen S. Medically unexplained physical symptoms. BMF 1991;303:1062.

5 International Association for the Study of Pain Subcommittee on Taxonomy. Classification of chronic pain. Pain 1986; suppl 3:217.

Hughes AM, Hunter S, Still D, Lamey PJ. Psychiatric disorders in a dental clinic. Br Dent $\mathcal{f}$ 1989;166:16-9.

Turk DC, Rudy TE. Neglected topics in the treatment of chronic pain patients-relapse, noncompliance, and adherence enhancement. Pain 1991;44:5-28.

Meichenbaum D, Turk DC. Facilitating treatment adherence: a practitioner's guidebook. New York: Plenum, 1987 .

Feinmann C, Harris M, Cawley R. Psychogenic facial pain: presentation and treatment. BMJ 1984;288:436-8.

10 Friesberg MK. Tricyclic antidepressants: analgesic effects and indications in orofacial pain. Fourmal of Craniomandibular Disorders: Facial and Oral Pain 1988;2:171-7.

11 Pilowsky I, Barrow CG. A controlled study of psychotherapy and amitriptyline used individually and in combination in the treatment of chronic intractable, "psychogenic" pain. Pain 1990;40:3-19.

12 Lamey PJ, Lamb AB. Prospective study of aetiological factors in burning mouth syndrome. $B M J$ 1988;297:1243-6.

13 Zitman FG, Linssen ACG, Edelbroek PM, Vankempen GMJ. Does addition of low dose flupenthixol enhance the analgesic effects of low dose amitriptyline in somatoform pain disorder? Pain 1991;47:25-30.

14 Bond M, Hughes AM. Psychological aspects of chronic pain. Int Disabil Stud 1987;9(1):23-7.

\section{Clinical review articles}

\section{Should be as scientific as the articles they review}

Much of medical knowledge is highly perishable. The first credible news of fresh advances appears in peer reviewed medical journals, but clinicians who try to upgrade their knowledge by reading medical journals face a formidable task. ${ }^{1}$ Most studies provide preliminary evidence at best because of limited scope, poor design or execution, or a sample size inadequate for important clinical benefits or adverse effects to be detected, or because of the play of chance. Thus the reader must appraise each report and compare and integrate it with previous evidence to reach a decision about whether clinical policy should be changed on the basis of the accumulated information.

Even when an original study is definitive by itself it will seldom address more than a portion of the clinical range of the problem. Inclusion and exclusion criteria for clinical trials, for example, typically select for the patients who are at highest risk of suffering bad consequences from their disorders and are most likely to respond to the intervention being tested, leaving the reader to speculate whether other patients might benefit.

Clinical readers may take a shortcut through this difficulty by reading review articles in which someone else has taken the trouble to round up the evidence from available studies on a clinical problem. But unless the review is constructed in an exacting fashion that does justice to the original evidence the reader may end up with false conclusions (the brunt of which may be borne by patients). Indeed, Mulrow found that none of 50 reviews published in four major American medical journals in 1985 and 1986 met all of eight criteria for scientifically sound summaries of evidence. ${ }^{2}$ Most distressingly, "Only one had clearly specified methods of identifying, selecting, and validating included information."

Following the pioneering work of Thomas Chalmers and his colleagues in resolving disputes in published medical work, ${ }^{3}$ Mulrow and others have called for more scientific procedures for review articles and Oxman and Guyatt have published a "reader's guide" for clinicians who want to be sure that a review article provides an unbiased view of the truth. ${ }^{4}$ To be true to evidence reviews must articulate a clear question or set of questions, find and select pertinent published (and sometimes unpublished) evidence in an unbiased and reproducible way, determine whether there is enough consistency in the studies to warrant pooling their results, characterise the findings in a way that is statistically valid, and reach a conclusion that readers can verify for themselves. Thus the reviewer should adhere to the same scientific principles in summarising studies as the investigators of those studies did (or should have done) in generating the original evidence. In other words, the review article itself should be the product of scientific investigation in which the participants are original investigations rather than patients.

These standards, crystallised by social scientists, ${ }^{5-7}$ have taken hold slowly in reviews of published biomedical reports over the past decade and are still far from the norm in the review articles that are published today. Buyer beware: unsystematic reviews lead to unsystematic conclusions. 